\title{
Fuzzy Entropy Construction based on Similarity Measure
}

\author{
Park, Hyun Jeong ${ }^{1}$, Insuk Yang ${ }^{2}$, Soorok $\mathrm{Ryu}^{2}$ and Sang H. Lee ${ }^{3 *}$ \\ 1 Department of Mathematics Education, Ewha Womans University \\ 2 Department of Industrial and Applied Mathematics, Kyungbuk National University \\ 3 School of Mechatronics, Changwon National University
}

\begin{abstract}
In this paper we derived fuzzy entropy that is based on similarity measure. Similarity measure represents the degree of similarity between two informations, those informations characteristics are not important. First we construct similarity measure between two informations, and derived entropy functions with obtained similarity measure. Obtained entropy is verified with proof. With the help of one-to-one similarity is also obtained through distance measure, this similarity measure is also proved in our paper.
\end{abstract}

Key Words : Similarity measure, distance measure, fuzzy entropy, one-to-one correspondence

\section{Introduction}

Obtaining of the degree of similarity between two or more data has central role for the fields of decision making, pattern classification, or etc.. Quantity of difference can be useful to discriminate or cluster for various informations. Until now the research of designing similarity measure has been made by numerous researchers[1-6]. For fuzzy set, there is an uncertainty knowledge in fuzzy set itself. Hence information of the data can be obtained from analyzing the fuzzy membership function. Thus most studies about fuzzy set are focussed on designing similarity measure based on membership function. In the previous results, similarity measures are obtained through fuzzy number[1-4]. Fuzzy number provide similarity measure easily. However considering similarity measures are restricted within triangular or trapezoidal membership func ${ }^{-}$ tions $[1-4]$. In this paper we try to analyze relations be ${ }^{-}$ tween fuzzy entropy and similarity. With the help of distance measure, we design the similarity measure. Proposed similarity measure produce fuzzy entropy based on relation between fuzzy entropy and similarity measure. Furthermore we have proved the entropy that is derived from similarity measure.

First we introduce the properties of fuzzy entropy, distance measure and similarity measure. Similarity measure is also proposed using distance measure. Proposed similarity measure construct fuzzy entropy with the relation of fuzzy entropy and similarity

접수일자 : 2007년 11월 20일

완료일자 : 2007년 12월 16일

*Corresponding Author

This work was supported by 2nd BK21 Program, which is funded by KRF (Korea Research Foundation). measure. Notations of this paper are used Liu's [7].

\section{Similarity measure and fuzzy entropy analysis}

In this chapter, introduction of fuzzy entropy and similarity measure are carried out. Furthermore similarity measures are also proposed with distance measure.

\subsection{Fuzzy entropy, similarity measure}

Fuzzy entropy represents the fuzziness of fuzzy set. Fuzziness of fuzzy set is represented through degree of certainty or uncertainty, hence the entropy is obtained from fuzzy membership function itself. Liu presented the axiomatic definitions of fuzzy entropy and similarity measure [7], and these definitions have the meaning of difference or closeness for different fuzzy membership functions. First we introduce fuzzy entropy. We design fuzzy entropy based on distance measure satisfying definition of fuzzy entropy.

Definition 2.1 [7] A real function $e: F(X) \rightarrow R^{+}$is called an entropy on $F(X)$, if $e$ has the following properties:

(E1) $e(D)=0, \forall D \in P(X)$

(E2) $e([1 / 2])=\max _{A \in F(X)} e(A)$

(E3) $e\left(A^{*}\right) \leq e(A)$, for any sharpening $A^{*}$ of $A$

(EA) $e(A)=e\left(A^{c}\right), \forall A \in F(X)$

where $[1 / 2]$ is the fuzzy set in which the value of the membership function is $1 / 2, R^{+}=[0, \infty), X$ is the universal set, $F(X)$ is the class of all fuzzy sets of $X$, $P(X)$ is the class of all crisp sets of $X$, and $D^{c}$ is the 
complement of $D$.

There are a lot of fuzzy entropy satisfying Definition 2.1. We have designed fuzzy entropy in our previous literature [10]. Hence two fuzzy entropy are illustrated without proofs.

Fuzzy entropy 1 . If distance $d$ satisfies $d(A, B)=d\left(A^{C}, B^{C}\right), A, B \in F(X)$, then

$$
e(A)=2 d\left(\left(A \cap A_{\text {near }}\right),[1]\right)+2 d\left(\left(A \cup A_{\text {near }}\right),[0]\right)-2
$$

is fuzzy entropy.

Fuzzy entropy 2 If distance $d$ satisfies $d(A, B)=d\left(A^{C}, B^{C}\right), A, B \in F(X)$, then

$$
e(A)=2 d\left(\left(A \cap A_{f a r}\right),[0]\right)+2 d\left(\left(A \cup A_{f a r}\right),[1]\right)
$$

is also fuzzy entropy.

Exact meaning of fuzzy entropy of fuzzy set $A$ is fuzzy entropy of fuzzy set $A$ with respect to crisp set of fuzzy set $A$. We commonly consider crisp set as $A_{\text {near }}$ or $A_{f a r}$. In the above fuzzy entropy. one of wellknown Hamming distance is commonly used as distance measure between fuzzy sets $A$ and $B$,

$$
d(A, B)=\frac{1}{n} \sum_{i=1}^{n}\left|\mu_{A}\left(x_{i}\right)-\mu_{B}\left(x_{i}\right)\right|
$$

where $X=x_{1}, x_{2}, \cdots x_{n},|k|$ is the absolute value of $k$. $\mu_{A}(x)$ is the membership function of $A \in F(X)$. Basically fuzzy entropy means the difference between two fuzzy membership functions. Next we will introduce the similarity measure, and it describes the degree of closeness between two fuzzy membership functions. It is also found in literature of Liu.

Definition 2.2 [7] A real function $s: F^{2} \rightarrow R^{+}$is called a similarity measure, if $s$ has the following properties:

$$
\begin{array}{ll}
\text { (S1) } s(A, B)=s(B, A), \forall A, B \in F(X) \\
\text { (S2) } s\left(D, D^{c}\right)=0, \forall D \in P(X) \\
\text { (S3) } s(C, C)=\max _{A, B \in F} s(A, B), \forall C \in F(X) \\
\text { (S4) } \forall A, B, C \in F(X), \quad \text { if } \quad A \subset B \subset C, \quad \text { then } \\
& s(A, B) \geq s(A, C) \text { and } s(B, C) \geq s(A, C) .
\end{array}
$$

Fuzzy normal similarity measure on $F$ is also obtained by the division of $\max _{C, D \in F} s(C, D)$. With Definition 2.2, we propose the following theorem as the similarity measure.

Theorem 2.1 For any set $A, B \in F(X)$, if $d$ satisfies Hamming distance measure and $d(A, B)=d\left(A^{C}, B^{C}\right.$, then

$$
s(A, B)=1-d\left(\left(A \cap B^{C}\right),[0]\right)-d\left(\left(A \cup B^{C}\right),[1]\right)
$$

is the similarity measure between set $A$ and set $B$. proof. Commutativity of (S1) is proved through

$$
\begin{aligned}
s(A, B) & =1-d\left(\left(A \cap B^{C}\right),[0]\right)-d\left(\left(A \cup B^{C}\right),[1]\right) \\
& =1-d\left(\left(A \cap B^{C}\right)^{C},[0]^{C}\right)-d\left(\left(A \cup B^{C}\right)^{C},[1]^{C}\right) \\
& =1-d\left(\left(B \cup A^{C}\right),[1]\right)-d\left(\left(B \cap A^{C}\right),[0]\right) \\
& =s(B, A) .
\end{aligned}
$$

To show the property of (S2),

$$
\begin{aligned}
s\left(A, A^{c}\right) & =1-d\left(\left(A \cap\left(A^{c}\right)^{c}\right),[0]\right)-d\left(\left(A \cup\left(A^{c}\right)^{c}\right),[1]\right) \\
& =1-(d(A,[0])+d(A,[1])) \\
& =1-1 \cdot 1=0
\end{aligned}
$$

is clear. (S3) is clear from the relation

$$
\begin{aligned}
s(A, B) & =1-d\left(\left(A \cap B^{c}\right),[0]\right)-d\left(\left(A \cup B^{c}\right),[1]\right) \\
& \leqq 1-d\left(\left(D \cap D^{c}\right),[0]\right)-d\left(\left(D \cup D^{c}\right),[1]\right) \\
& =s(D, D),
\end{aligned}
$$

where the inequality is proved by

$$
\begin{aligned}
& d\left(\left(A \cap B^{c}\right),[0]\right) \geqq d\left(\left(D \cap D^{c}\right),[0]\right) \text { and } \\
& d\left(\left(A \cup B^{c}\right),[1]\right) \geqq d\left(\left(D \cup D^{c}\right),[1]\right) .
\end{aligned}
$$

Finally, $\forall A, B, C \in F(X)$ and $A \subset B \subset C$ imply

$$
\begin{aligned}
s(A, B) & =1-d\left(\left(A \cap B^{c}\right),[0]\right)-d\left(\left(A \cup B^{c}\right),[1]\right) \\
& =1-d([0],[0])-d\left(\left(A \cup B^{c}\right),[1]\right) \\
& \geqq 1-d\left(A \cap C^{c},[0]\right)-d\left(A \cup C^{c},[1]\right) \\
& =1-d([0],[0])-d\left(A \cup C^{c},[1]\right) \\
& =s(A, C) . \\
s(B, C) & =1-d\left(\left(B \cap C^{c}\right),[0]\right)-d\left(\left(B \cup C^{c}\right),[1]\right) \\
& =1-d([0],[0])-d\left(\left(B \cup C^{c}\right),[1]\right) \\
& \geqq 1-d\left(A \cap C^{c},[0]\right)-d\left(A \cup C^{c},[1]\right) \\
& =1-d([0],[0])-d\left(A \cup C^{c},[1]\right) \\
& =s(A, C)
\end{aligned}
$$

is also satisfied with $d\left(\left(A \cup B^{c}\right),[1]\right) \geqq d\left(\left(A \cup C^{c}\right),[1]\right)$ and $d\left(\left(B \cup C^{c}\right),[1]\right) \geqq d\left(\left(A \cup C^{c}\right),[1]\right)$.

We have proposed the similarity measure that are induced from distance measure. This similarity is useful for the non interacting fuzzy membership function pair. Another similarity is also obtained, and it can be found in our previous literature [6].

Theorem 2.2 For any set $A, B \in F(X)$ if $d$ satisfies Hamming distance measure, then

$$
s(A, B)=2-d((A \cap B),[1])-d((A \cup B),[0])
$$

is the similarity measure between set $A$ and set $B$. To be a similarity measure, Theorem 2.2 does not need condition $d(A, B)=d\left(A^{C}, B^{C}\right)$. Because commutativity is 
clear from the theorem itself. Also this similarity (2) is useful for the interacting membership function pair.

Liu also pointed out that there is an one-to- ${ }^{-}$one relation between all distance measures and all similarity measures, $d+s=1$. In the next section, we derive similarity measure that is generated by distance measure. Furthermore entropy is derived through similarity measure by the properties of Liu.

\subsection{One-to-one correspondence}

It is obvious that next Hamming distance is represented as

$$
d(A, B)=d((A \cap B),[1])-(1-d((A \cup B),[0])) .
$$

Where $\quad A \cap B=\min \left(\mu_{A}\left(x_{i}\right), \mu_{B}\left(x_{i}\right)\right) \quad$ and $A \cup B=\max \left(\mu_{A}\left(x_{i}\right), \mu_{B}\left(x_{i}\right)\right)$ are satisfied. With the Proposition 3.4 of Liu[7], we can generate the similarity measure or distance measure through distance measure or similarity measure [7].

Proposition 2.1[7] There exists an one-to-one correlation between all distance measures and all similarity measures, and a distance measure $d$ and its corresponding similarity measure $s$ satisfy $s+d=1$.

With the property of $s=1-d$, we can construct the similarity measure generated by distance measure $d$, that is $s\langle d\rangle$. From (3) it is natural to obtain following result.

$$
\begin{aligned}
d(A, B) & =d((A \cap B),[1])+d((A \cup B),[0])-1 \\
& =1-s(A, B)
\end{aligned}
$$

Therefore we propose the similarity measure with above expression.

$$
s<d \geqq 2-d((A \cap B),[1])-d((A \cup B),[0])
$$

This similarity measure is exactly same with (2). At this point, we verified the one-to-one relation of distance measure and similarity measure. In the next chapter, we verify that the fuzzy entropy is derived through similarity (2).

\section{Entropy derivation with similarity measure}

Liu also suggested propositions about entropy and similarity measure. He also insisted that the entropy can be generated by similarity measure and distance measure, those are denoted by $e\langle s\rangle$ and $e\langle d\rangle$.

\subsection{Entropy generation by similarity}

Proposition 3.5 and 3.6 of reference [7] are summarized as follows.
Proposition 3.1 [7] If $s$ is a similarity measure on $F$, define

$$
e(A)=s\left(A, A^{c}\right), \quad \forall A \in F \text {. }
$$

Then $e$ is an entropy on $F$.

Now we check whether our similarities (1) and (2) satisfy Proposition 3.1. Proof can be obtained by checking whether

$$
s\left(A, A^{c}\right)=2-d\left(\left(A \cap A^{c}\right),[1]\right)-d\left(\left(A \cup A^{c}\right),[0]\right)
$$

satisfy from (E1) to (EA) of Definition 2.1.

For (E1), $\forall D \in P(X)$,

$$
\begin{aligned}
s\left(D, D^{c}\right) & =2-d\left(\left(D \cap D^{c}\right),[1]\right)-d\left(\left(D \cup D^{c}\right),[0]\right) \\
& =2-d([0],[1])-d([1],[0])=0
\end{aligned}
$$

(E2) represents that crisp set $1 / 2$ has the maximum entropy value. Therefore, the entropy $e([1 / 2])$ satisfies

$$
\begin{aligned}
s\left([1 / 2],[1 / 2]^{c}\right)= & 2-d\left(\left([1 / 2] \cap[1 / 2]^{c}\right),[1]\right) \\
& -d\left(\left([1 / 2] \cup[1 / 2]^{c}\right),[0]\right) \\
= & 2-d([1 / 2],[1])-d([1 / 2],[0]) \\
= & 2-1 / 2-1 / 2=1
\end{aligned}
$$

In the above equation, $[1 / 2]^{c}=[1 / 2]$ is satisfied.

(E3) shows that the entropy of the sharpened version of fuzzy set $A, e\left(A^{*}\right)$, is less than or equal to $e(A)$.

$$
\begin{aligned}
s\left(A^{*}, A^{*}\right) & =2-d\left(\left(A^{*} \cap A^{*} c\right),[1]\right)-d\left(\left(A^{*} \cup A^{*} c\right),[0]\right) \\
& \leqq 2-d\left(\left(A \cap A^{c}\right),[1]\right)-d\left(\left(A \cup A^{c}\right),[0]\right) \\
& =s\left(A, A^{c}\right)
\end{aligned}
$$

Finally, (E4) is proved directly

$$
\begin{aligned}
s\left(A, A^{c}\right) & =2-d\left(\left(A \cap A^{c}\right),[1]\right)-d\left(\left(A \cup A^{c}\right),[0]\right) \\
& =2-d\left(\left(A^{c} \cap A\right),[1]\right)-d\left(\left(A^{c} \cup A\right),[0]\right) \\
& =s\left(A^{c}, A\right)
\end{aligned}
$$

From the above proof, our similarity measure

$$
s\left(A, A^{c}\right)=2-d\left(\left(A \cap A^{c}\right),[1]\right)-d\left(\left(A \cup A^{c}\right),[0]\right)
$$

generate fuzzy entropy.

Next another similarity (1) between $A$ and $A^{c}$ is

$$
\begin{gathered}
s\left(A, A^{c}\right)=1-d((A \cap A),[0])-d((A \cup A),[1]) \\
=1-d(A,[0])-d(A,[1]) .
\end{gathered}
$$

This similarity always satisfies zero.

For (E1), $\forall D \in P(X)$,

$$
s\left(D, D^{c}\right)=1-d(D,[0])-d(D,[1])=0
$$

(E2), $s\left([1 / 2],[1 / 2]^{c}\right)=1-d([1 / 2],[0])-d([1 / 2],[1])=0$ 
For (E3), $s\left(A^{*}, A^{*}\right)=s\left(A, A^{c}\right)=0$

Finally, (EA) is proved similarly

$$
s\left(A, A^{c}\right)=s\left(A^{c}, A\right)=0 .
$$

From the above proof, our similarity measure

$$
s\left(A, A^{c}\right)=1-d((A \cap A),[0])-d((A \cup A),[1])
$$

generate fuzzy entropy trivially.

This fact inform that the similarity between two fuzzy membership function contain two common parts.

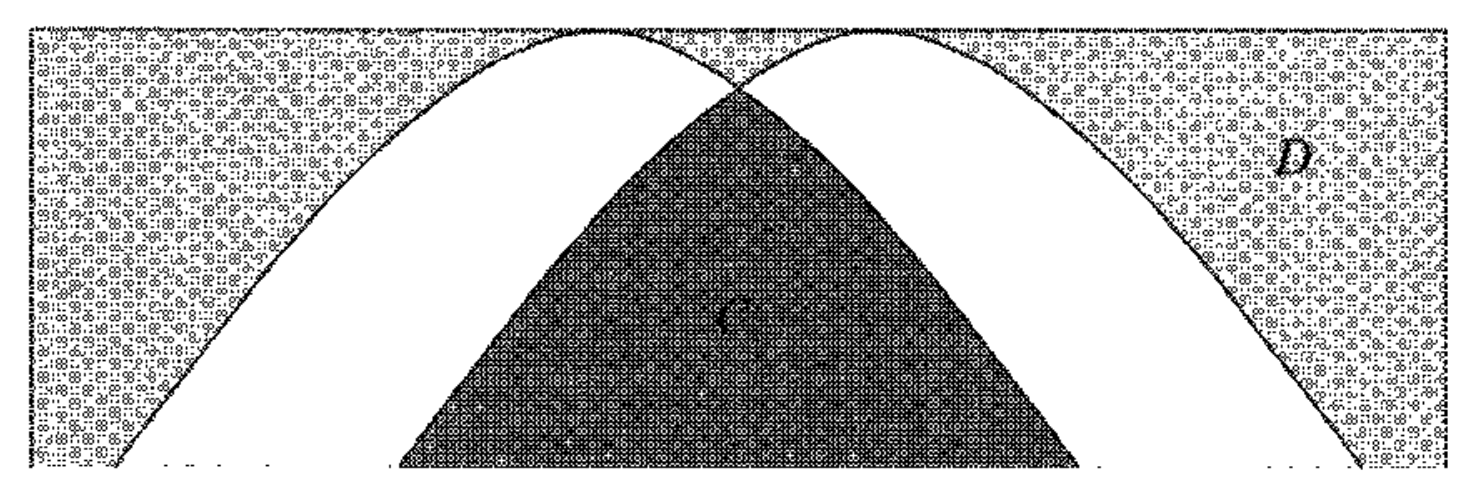

Fig. 1. Gaussian type two membership functions

Area $C$ and $D$ are both common area of two membership function. It is questionable area $D$ satisfy common area of two membership function. However property (S4) in Definition 2.2 tell us that area $D$ satisfy naturally $s(A, B) \geq s(A, C)$ and $s(B, C) \geq s(A, C)$, if $A \subset B \subset C$.

\subsection{Relation of similarity and distance}

With the property of one-to-one correspondence be ${ }^{-}$ tween similarity and distance, we have derived fuzzy entropies. For the derivation of similarity measure, $s=1-d$ is also used. If we use distance measure (3)

$$
d(A, B)=d((A \cap B),[1])-(1-d((A \cup B),[0])),
$$

we obtain the corresponding similarity measure

$$
s<d \geqq 2-d((A \cap B),[1])-d((A \cup B),[0]) .
$$

then this similarity is identical to (2).

From another similarity (1)

$$
s(A, B)=1-d\left(\left(A \cap B^{C}\right),[0]\right)-d\left(\left(A \cup B^{C}\right),[1]\right),
$$

is $d(A, B)=d\left(\left(A \cap B^{C}\right),[0]\right)+d\left(\left(A \cup B^{C}\right),[1]\right)$ satisfied ?

By the definition of distance measure of Liu [7],

$$
\begin{aligned}
& \qquad \begin{aligned}
d(A, B) & =d\left(\left(A \cap B^{C}\right),[0]\right)+d\left(\left(A \cup B^{C}\right),[1]\right) \\
& =d\left(\left(A \cap B^{C}\right)^{C},[0]^{C}\right)+d\left(\left(A \cup B^{C}\right)^{C},[1]^{C}\right) \\
& =d\left(\left(A A^{C} \cup B\right),[1]\right)+d\left(\left(A^{C} \cap B\right),[0]\right) \\
& =d(B, A) . \\
d(A, A) & =d\left(\left(A \cap A^{C}\right),[0]\right)+d\left(\left(A \cup A^{C}\right),[1]\right) \\
& =d([0],[0])+d([1],[1])=0 . \\
\text { For } d(A, B) & =d\left(\left(A \cap B^{C}\right),[0]\right)+d\left(\left(A \cup B^{C}\right),[1]\right) \\
& \leqq d\left(\left(D \cap D^{C}\right),[0]\right)+d\left(\left(D \cup D^{C^{C}}\right),[1]\right) \\
& =d((D \cap D),[0])+d((D \cup D),[1])
\end{aligned}
\end{aligned}
$$

$$
=d(D,[0])+d(D,[1])=1 \text {. }
$$

Hence it is natural that distance between crisp set and its complement become maximal value. Finally,

$$
\begin{aligned}
d(A, B) & =d\left(\left(A \cap B^{C}\right),[0]\right)+d\left(\left(A \cup B^{C}\right),[1]\right) \\
& \leqq d\left(\left(A \cap C^{C}\right),[0]\right)+d\left(\left(A \cup C^{C}\right),[1]\right) \\
& =d(A, C)
\end{aligned}
$$

and

$$
\begin{aligned}
d(B, C) & =d\left(\left(B \cap C^{C}\right),[0]\right)+d\left(\left(B \cup C^{C}\right),[1]\right) \\
& \leqq d\left(\left(A \cap C^{C}\right),[0]\right)+d\left(\left(A \cup C^{C}\right),[1]\right) \\
& =d(A, C)
\end{aligned}
$$

are satisfied because of inclusion property, $A \subset B \subset C$.

In this section we have verified the relation between similarity measure and distance measure. Derivation of distance measure from similarity measure is obtained easily.

\section{Conclusions}

We have derived the similarity measure that is $\mathrm{de}^{-}$ rived from distance measure. The proposed similarity usefulness is proved. Furthermore with the relation between fuzzy entropy and similarity measure we also verified that the fuzzy entropy is induced through similarity measure. In this paper our proposed similarity measures are provided for the design of fuzzy entropy. Among the proposed similarity measure, a similarity satisfy fuzzy entropy trivially. Even though there are similarity measure satisfying similarity definition, there can exist trivial fuzzy entropy. Finally, proposed similarity measure can be applied to the general types of fuzzy membership functions.

\section{References}

[1] S.M. Chen, "New methods for subjective mental workload assessment and fuzzy risk analysis", Cybern. Syst. : Int. J., vol 27, no. 5, 449-472, 1996.

[2] C.H. Hsieh and S.H. Chen, "Similarity of generalized fuzzy numbers with graded mean integration representation," in Proc. 8th Int. Fuzzy Systems Association World Congr., vol 2, 551-555, 1999.

[3] HS. Lee, "An optimal aggregation method for fuzzy opinions of group decision," Proc. 1999 IEEE Int. Conf. Systems, Man, Cybernetics, vol. 3, 314-319, 1999.

[4] S.J. Chen and S.M. Chen, "Fuzzy risk analysis based on similarity measures of generalized fuzzy numbers," IEEE Trans. on Fuzzy Systems, 
vol. 11, no. 1, 45-56, 2003.

[5] S.H. Lee, S.P. Cheon, and Jinho Kim, "Measure of certainty with fuzzy entropy function", LNAI, Vol. 4114, 134-139, 2006.

[6] S.H. Lee, J.M. Kim, and Y.K. Choi, "Similarity measure construction using fuzzy entropy and distance measure", LNAI, Vol. 4114, 952-958, 2006.

[7] X. Liu, "Entropy, distance measure and similarity measure of fuzzy sets and their relations," Fuzzy Sets and Systems, 52, 305-318, 1992.

[8] J. L. Fan, W. X. Xie, "Distance measure and induced fuzzy entropy," Fuzzy Set and Systems, 104, 305-314, 1999.

[9] J. L. Fan, Y. L. Ma, and W. X. Xie, "On some properties of distance measures," Fuzzy Set and Systems, 117, 355-361, 2001.

[10] S. H. Lee, Y. T. Kim, S. P. Cheon and S. S. Kim, "Reliable data selection with fuzzy entropy," LNAI, Vol. 3613, 203-212, 2005.

\section{저 자 소 개}

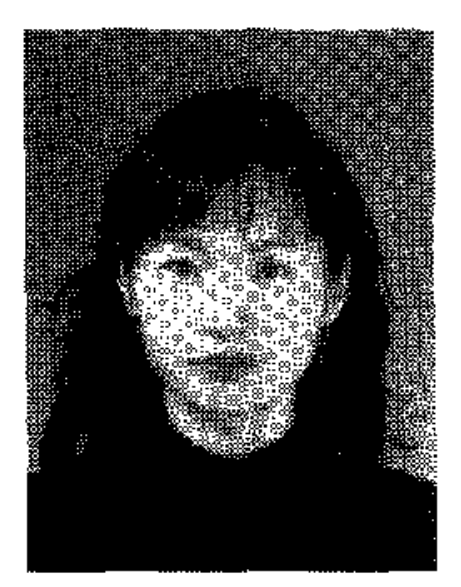

박현 정 (Park, Hyun-Jeong)

1992년 : 경희대학교 수학과(이학사)

2001년 : 이화여자대학교 수학교육과 (교육학석사)

2007년 : 이화여자대학교 수학교육과 (교육학박사)

관심분야: fuzzy theory, evaluation theory, math. education

E-mai : hyunjp@ewhain.net

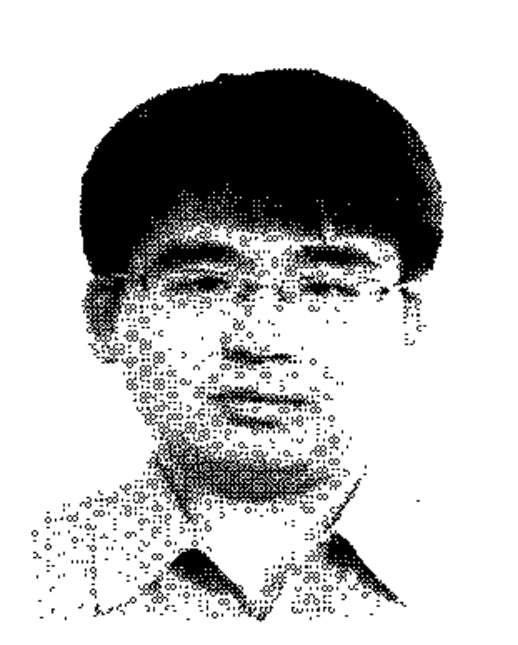

양인 석(Insuk Yang)

2001년 : 경북대학교 수학과(이학사)

2006년 : 경북대학교 산업응용수학과(이 학석사)

2006년 경북대학교 수학부 박사과정

관심분야 : numerical PDE, optimal control, fluid mechanics

E-mail : jewill@hannail.net

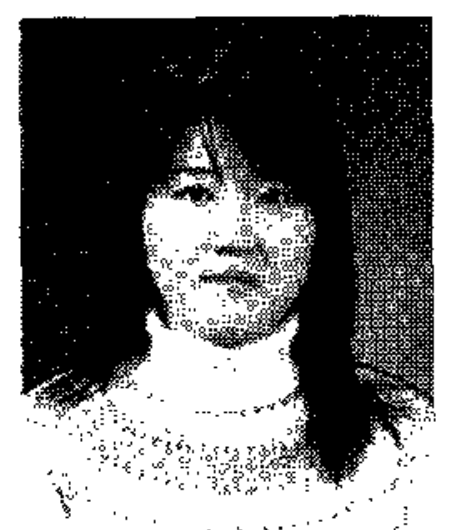

류수록(Soorok Ryu)

2003년 : 경북대학교 수학과(이학사)

2005년 : 경북대학교 산업응용수학과 (이학석사)

2005년 경북대학교 수학부 박사과정 수로

관심분야: numerical PDE, optimal control, fluid mechanics

E-mail : sryu@knu.ac.kr

이상혁(Sang-Hyuk Lee)

제 17권 1호. (2007년 2월호) 참조

E-mail : leehyuk@changwon.ac.kr 